\title{
CONF-96/202- -37
}

Note: This is a preprint of a paper being submitted for publication. Contents of this paper should not be quoted nor referred to without permission of the author(s).

MRS 1996 Fall Meeting

Boston, MA

\section{CHARGE STATE DEFECT ENGINEERING OF SILICON DURING ION IMPLANTATION}

R. A. Brown, G. A. Rozgonyi

North Carolina State University, Raleigh, NC

J. Ravi

SEH America, Vancouver, WA

Y. Erokhin

Eaton Corp., Beverley, MA

C. W. White

Oak Ridge National Laboratory, Oak Ridge, TN

"The submitted manuscript has been
authored by a contractor of the U.S.
Government under contract No. DE-AC05-
$960 R 22464$. Accordingly, the U.S.
Government retains a nonexclusive,
royalty-free license to publish or
reproduce the published form of this
contribution, or allow others to do so, for
U.S. Government purposes."

Prepared by the

Oak Ridge National Laboratory

Oak Ridge, Tennessee 37831

managed by

LOCKHEED MARTIN ENERGY RESEARCH CORP.

for the

U.S. DEPARTMENT OF ENERGY

under contract DE-AC05-96OR22464

January 1997

DISTRIBUTION OF THIS DOCMMENT IS UNLMITED 


\section{DISCLAIMER}

Portions of this document may be illegible in electronic image products. Images are produced from the best available original document. 


\section{CHARGE STATE DEFECT ENGINEERING OF SILICON DURING ION}

\section{IMPLANTATION}

R. A. BROWN*, J. RAVI*†, Y. EROKHIN* ${ }^{* \ddagger}$, G. A. ROZGONYI* AND C. W. WHITE*

* Department of Materials Science and Engineering, North Carolina State University, Raleigh, NC 27695-7916

** Solid State Division, Oak Ridge National Laboratory, TN 37831

$\dagger$ Present address: SEH America, 4111 N.E. 112th Avenue, Vancouver WA 9868

$\ddagger$ Present address: Eaton Corp., 108 Cherry Hill Dr., Beverley MA 01915

RECEIVED

JAN 281997

ABSTRACT

OSTI

The effects of in situ interventions which alter defect interactions during implantation, and thereby affect the final damage state, have been investigated. Specifically, we examined the effects of internal electric fields and charge carrier injection on damage accumulation in silicon. In the first part of this work, we implanted $\mathrm{H}$ or $\mathrm{He}$ ions into diode structures which were either reverse or forward biased during implantation. In the second part, we implanted B or Si ions into plain silicon wafers whilst illuminating them with UV light. In each case, the overall effect is one of damage reduction. Both the electric field and charge carrier injection effects may be understood as resulting from changes in defect interactions caused in part by changes to the charge state of defects formed during implantation.

\section{INTRODUCTION}

Despite decades of research, the interactions between simple defects that control the formation of more stable defect complexes during ion implantation are still not fully understood. Yet a detailed understanding of defect accumulation during ion implantation is of both fundamental and technological importance. In the present study, we have investigated the effects of in situ interventions which alter these defect reactions during implantation, and thereby affect the final damage state. Specifically, we examined the effects of internal electric fields and charge carrier injection on damage accumulation in silicon. In the first part of this work, we implanted $\mathrm{H}$ or He ions into diode structures which were either reverse or forward biased during implantation. We used deep-level transient spectroscopy to study the concentrations of deep level traps produced by $\mathrm{H}$ or $\mathrm{He}$ irradiation as a function of reverse bias voltage or forward current density. In the second part, we used Rutherford backscattering spectrometry and secondary ion mass spectroscopy to investigate the effect of UV illumination during implantation of boron or silicon ions.

\section{EXPERIMENT}

For the diode experiments, $1 \times 1 \mathrm{~mm}^{2}$ diode structures were fabricated on $n$-type Czochralski-grown $(\mathrm{Cz})$ silicon substrates with carrier concentrations of $\simeq 2 \times 10^{15} \mathrm{~cm}^{-3}$. These diodes were either (i) reverse biased during implantation of $150 \mathrm{keV} \mathrm{H}$ or $500 \mathrm{keV}$ 
He ions, or (ii) forward biased during implantation of $75 \mathrm{keV}$ He ions at room temperature. Deep levels produced by the implantation were investigated by Deep Level Transient Spectroscopy (DLTS) using the lock-in correlation technique.

For the UV experiments, unprocessed $n$-type $\mathrm{Cz}$ silicon wafers of $10-20 \Omega$-cm resistivity were attached to a nickel block with silver paste. In one case, the nickel block was cooled with liquid nitrogen while the sample was illuminated with a mercury arc lamp at a power density of $\simeq 700 \mathrm{~mW} \mathrm{~cm}^{-2}$. The resulting sample temperature was measured to be $\simeq 180 \mathrm{~K}$ by a thermocouple mounted on the wafer surface. Control samples were obtained by heating them to $180 \mathrm{~K}$ with no illumination. In either case, the samples were implanted with either $150 \mathrm{keV}, 1 \times 10^{14} \mathrm{~cm}^{-2}{ }^{30} \mathrm{Si}$ or $35 \mathrm{keV}, 5 \times 10^{14} \mathrm{~cm}^{-2}{ }^{11} \mathrm{~B}$ ions at ion fluxes of $2 \times 10^{11}$ and $4 \times 10^{11} \mathrm{~cm}^{-2} \mathrm{~s}^{-1}$ for silicon ions, and $2.5 \times 10^{13}$ and $5.0 \times 10^{13} \mathrm{~cm}^{-2} \mathrm{~s}^{-1}$ for boron ions. After implantation, the boron implanted samples were annealed in a vacuum furnace at $800^{\circ} \mathrm{C}$ for 30 minutes. The as-implanted damage was evaluated by Rutherford backscattering spectrometry/channeling (RBS), and the depth profiles of implanted boron were measured by Secondary Ion Mass Spectrometry (SIMS)

\section{RESULTS AND DISCUSSION}

To investigate the effect of an electric field on defect formation, reverse biases of 5-25 V were applied during implantation. The application of an electric field during implantation causes two effects. At reverse biases $\leq 5 \mathrm{~V}$, the ions are implanted through the spacecharge region (SCR) into the neutral $n$-type substrate, where the Fermi level is close to the conduction band. At reverse bias voltages $\gtrsim 10 \mathrm{~V}$, the SCR expands to include the implanted region: the Fermi level shifts to the middle of the band gap. Defects giving rise to deep level traps which were previously between the Fermi level and the middle of the band gap can now change charge state. A second, related effect is that charged, mobile defects can be redistributed by the electric field.

Fig. 1 shows typical DLTS spectra from the diode structures following implantation with (a) $\mathrm{H}$, and (b) He ions. In total, six distinct peaks were observed, corresponding to vacancy-oxygen complexes ( $\mathrm{V}-\mathrm{O}, \mathrm{E} 1)$, divacancies in the double negative charge state $\left(\mathrm{V}-\mathrm{V}^{=}, \mathrm{E} 2\right)$, hydrogen-related complexes (E3 and E5), a combination of divacancies in the singly-negative charge state $\left(\mathrm{V}-\mathrm{V}^{-}\right)$and phosphorus-vacancy complexes (P-V) (E4), and an unidentified peak (E6) which was only observed in the He-implanted samples [1].

We found that the electric field changed the concentration of each trap, but did not appear to redistribute them in depth on a macroscopic scale [1-3]. Fig. 2 shows the effect of reverse bias voltage on the concentration of deep traps $\left(N_{T}(\right.$ test $\left.)\right)$, normalized to the concentration measured in samples with no applied bias $\left(N_{T}(\mathrm{ref})\right)$ and plotted as a 'suppression' factor, i.e., $N_{T}$ (ref) $/ N_{T}$ (test). The concentration of each of the six observed deep traps was found to decrease with increasing bias voltage, with two exceptions. Firstly, the concentration of $\mathrm{E} 1$ traps ( $\mathrm{V}-\mathrm{O}$ complexes) was found to increase with reverse bias voltage for both $\mathrm{H}$ and $\mathrm{He}$ implantation. We believe this results from an increased interaction 
volume of migrating vacancies with the intrinsic oxygen in the $\mathrm{Cz}$ wafer, which is present at a concentration of $\sim 10^{18} \mathrm{~cm}^{-3}$. Secondly, with increasing bias, the concentration of E4 traps ( $\mathrm{V}-\mathrm{V}^{-}$and $\left.\mathrm{P}-\mathrm{V}\right)$ decreased in $\mathrm{H}$-implanted samples, but increased in He-implanted samples. However, we believe this difference is due to defect passivation in the H-implanted samples.
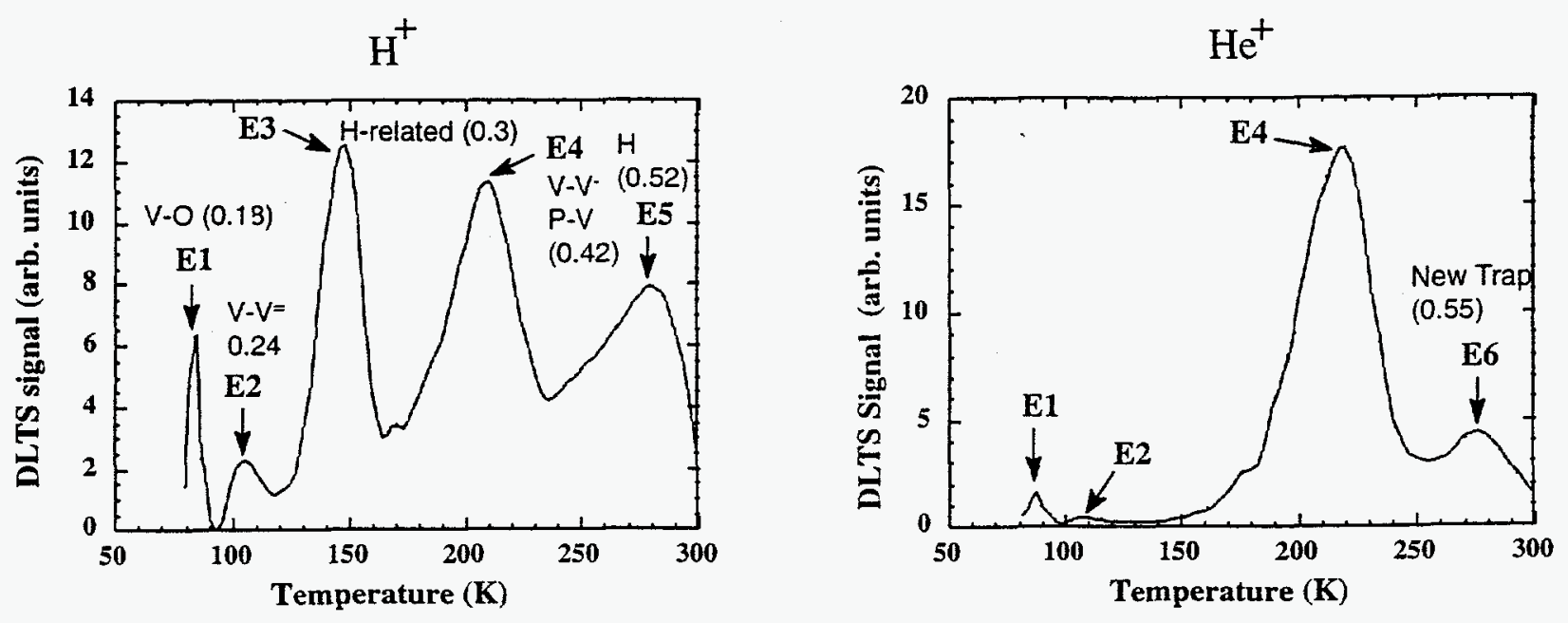

Figure 1: Typical DLTS spectra from samples implanted with (a) $\mathrm{H}$ and (b) He ions. The spectra show six peaks, corresponding to $\mathrm{V}-\mathrm{O}$ complexes (E1), $\mathrm{V}-\mathrm{V}=(\mathrm{E} 2)$, H-related complexes (E3, E5), V-V $\mathrm{V}^{-}$and P-V (E4), and an unidentified trap, E6.

Overall, we found the total number of traps generated by implantation to decrease with applied bias, an effect we attribute to enhanced defect annihilation. For a reverse bias of $10 \mathrm{~V}$, the incident ions are implanted into the SCR; hence the Fermi level is already at the middle of the band gap, and further increases of bias voltage only act to increase the electric field strength. Nevertheless, fig. 2 clearly indicates further changes in defect concentrations at 25 and $35 \mathrm{~V}$. Thus the mechanism cannot be solely the change in defect charge state, but also redistribution of mobile, charged defects under the influence of the electric field.

We also investigated the effect of charge carrier injection by implanting into forwardbiased diodes. We chose $75 \mathrm{keV}$ He ions so that the point defect and ion profiles fell within the space-charge region. The suppression of deep levels as a function of forward current density is shown in fig. 3 . In this case, the concentration of each deep level was never greater than in the reference (i.e., zero-biased) case. It is interesting that we observed no suppression at $1.0 \mathrm{~A} \mathrm{~cm}^{-2}$ for the $\mathrm{E} 2$ and $\mathrm{E} 4$ levels, when both levels were suppressed at both higher and lower forward current densities.

In the forward bias case, we are injecting charge carriers into the space-charge region. Thus we envisage two possible effects for the observed suppression. Firstly, the excess 

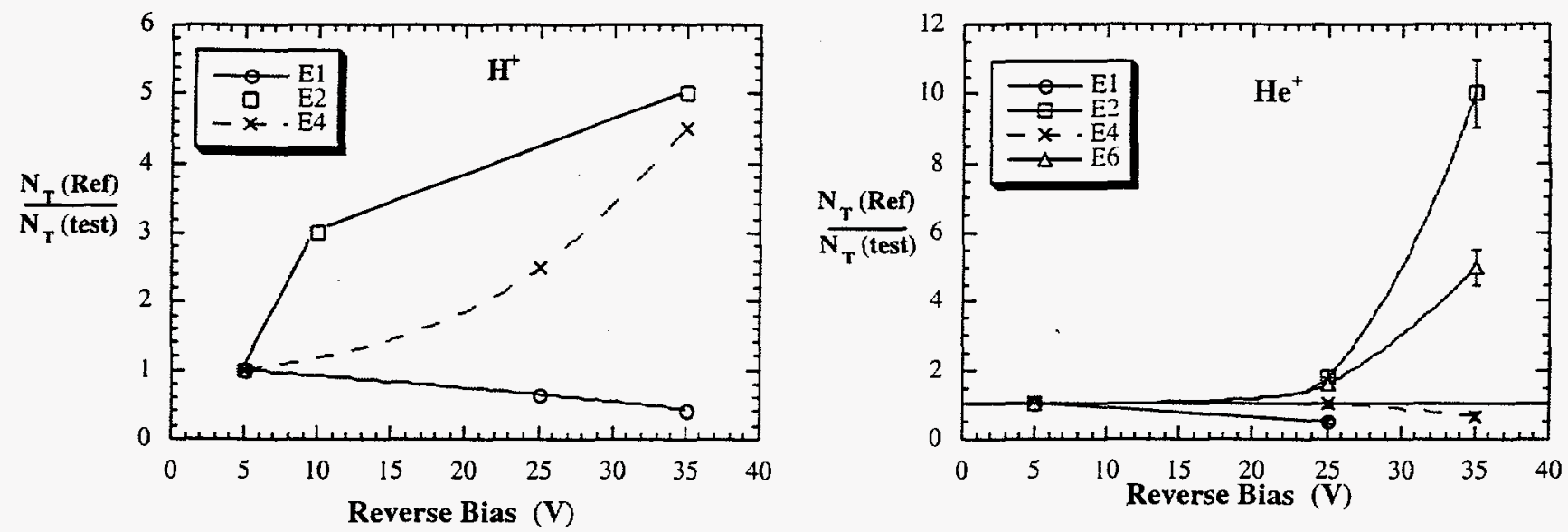

Figure 2: Deep level suppression as a function of reverse bias for (a) $\mathrm{H}$, and (b) $\mathrm{He}$ implantation. Overall, the number of deep levels was found to decrease with increasing bias, although the V-O (E1) peak increased in both cases, and E4 increased in He implanted samples.

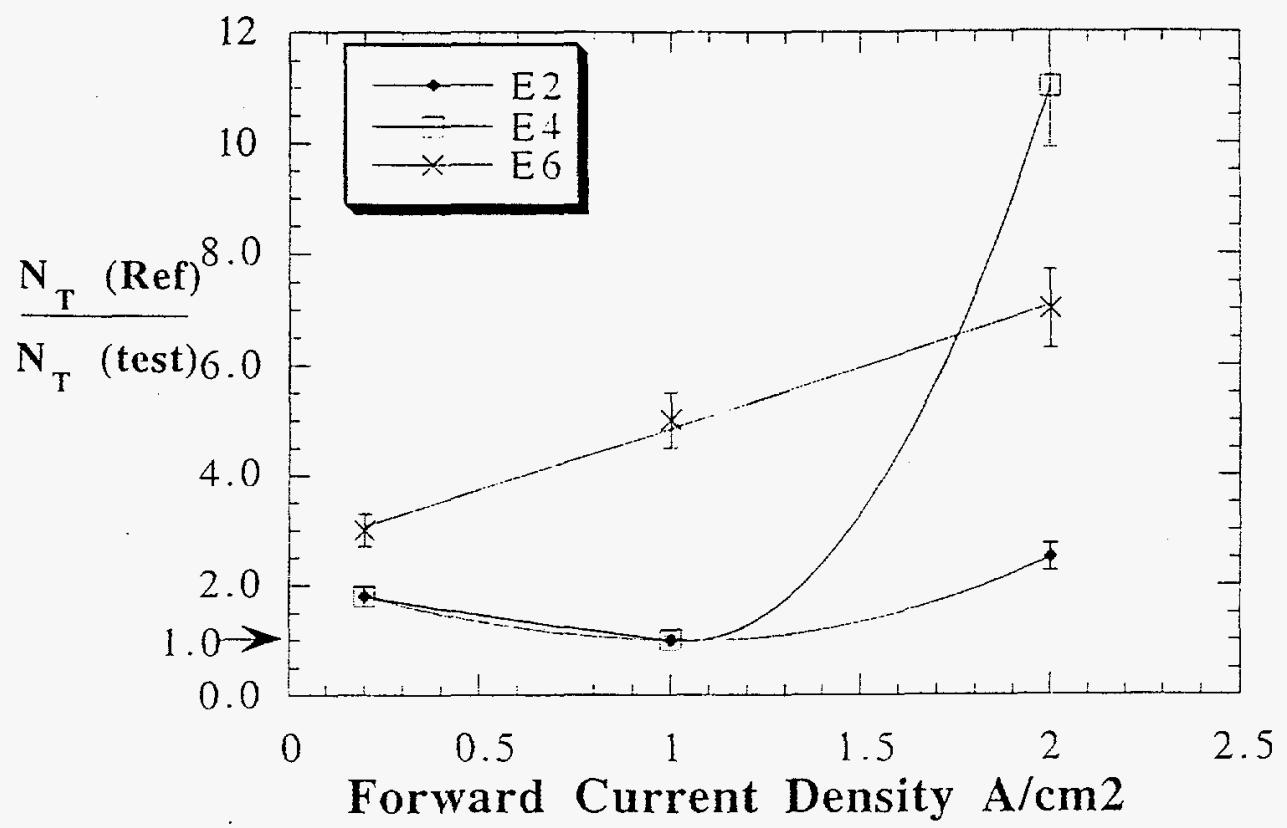

Figure 3: Deep level suppression as a function of forward current density for He implantation. The number of deep levels was found to decrease with increasing bias, although the $\mathrm{E} 2$ and $\mathrm{E} 4$ levels were unchanged at $1 \mathrm{~A} \mathrm{~cm}^{-2}$.

charge carriers may be captured by defects, thereby changing their charge state. Secondly, since silicon has an indirect band gap, recombination of charge carriers should be enhanced at deep levels. This can lead to an effective lowering of energy barriers at the defect site, an effect referred to as 'recombination-enhanced defect reactions' [4]. However, forward 
biasing of the diodes after implantation was not found to decrease their concentration. Therefore, enhanced annealing of simple defect complexes does not seem to be important, and we believe the dominant effect lies in their altered formation kinetics.

We also investigated the effects of charge carrier injection during implantation of high fluences of heavier ions by illuminating plain silicon wafers with UV radiation. To counter sample heating by the intense $\left(700 \mathrm{~mW} \mathrm{~cm}^{-2}\right) \mathrm{UV}$, we mounted our samples on a nickel block that was cooled with liquid nitrogen. Previously, we reported that the UV had a dramatic effect on damage suppression during implantation of $150 \mathrm{keV}, 1 \times 10^{14} \mathrm{~cm}^{-2} \mathrm{Si}$ ions [5]; however, we subsequently found that, even with this cooling, the sample temperature rose to $\simeq 180 \mathrm{~K}$ when the UV lamp was turned on. To compensate for this sample heating, we performed control experiments by implanting into samples that were heated to $180 \mathrm{~K}$ with no UV. These new results show that, although the suppression is not as great as previously reported, the UV still reduces the amount of residual damage measured by RBS. Fig 4 (a) shows the amount of damage suppression as a function of $\mathrm{Si}$ ion flux. Although the damage is reduced by a factor of 2.6 at a flux of $2 \times 10^{11} \mathrm{Si} \mathrm{cm}^{-2} \mathrm{~s}^{-1}$, there is almost no difference between samples implanted at a flux of $2.8 \times 10^{12} \mathrm{Si} \mathrm{cm}^{-2} \mathrm{~s}^{-1}$ with or without UV. We attribute this effect as due to the formation of more stable damage structures from interacting defects generated in overlapping cascades at high ion fluxes [6].
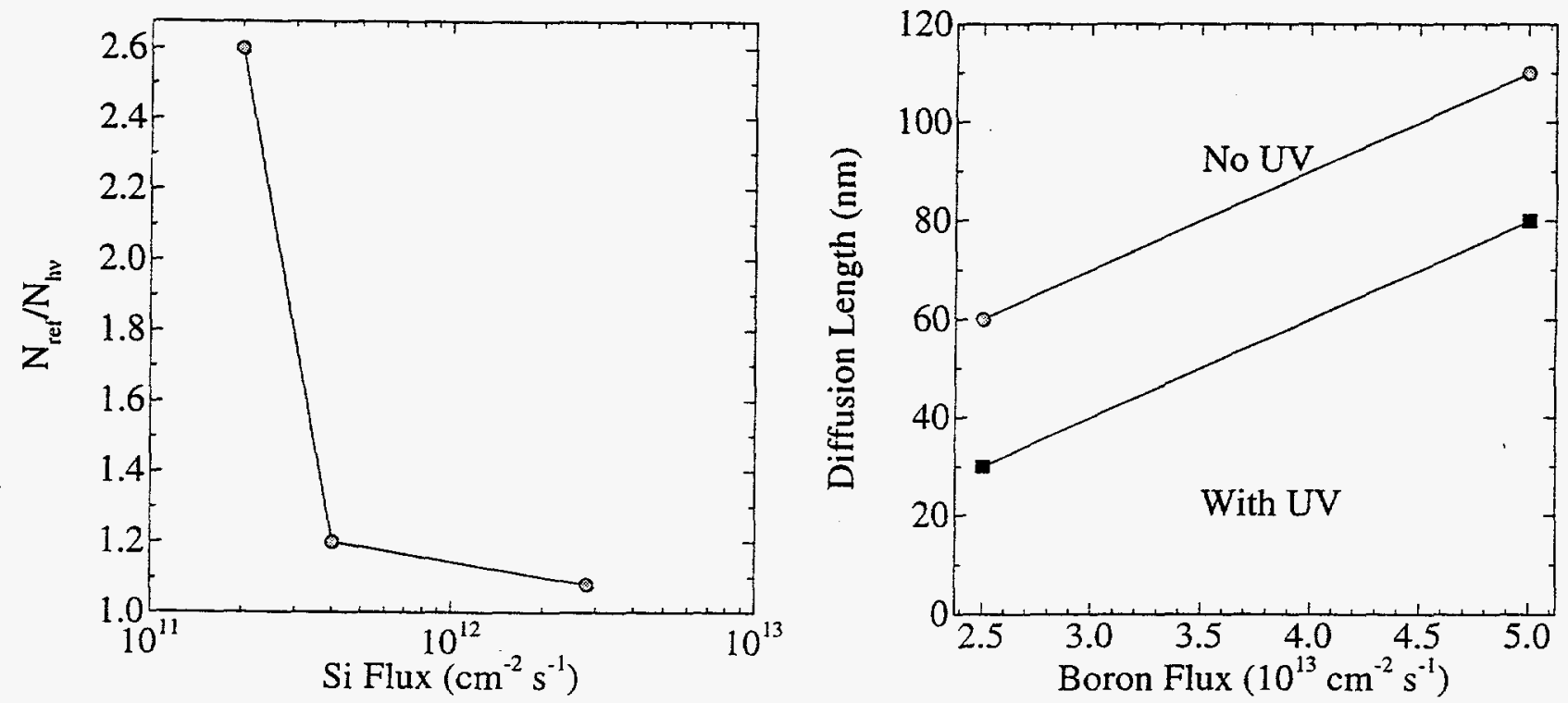

Figure 4: The effect of ion flux on UV damage suppression for (a) silicon implantation, and (b) boron implantation. In (a), the suppression of as-implanted damage (as measured by RBS) is plotted, showing that the UV has almost no effect at high ion fluxes. In (b), the diffusion length of boron in annealed samples is shown as a function of boron flux for samples with and without UV.

We observed a similar flux effect for boron implantation. We have already shown that UV reduces the degree of reverse annealing and enhanced diffusion of samples implanted 
with $35 \mathrm{keV}, 5 \times 10^{14} \mathrm{~B} \mathrm{~cm}^{-2}$ [7]. Fig. 4(b) shows the effect of boron ion flux on the diffusion length measured at a boron concentration of $1 \times 10^{17} \mathrm{~B} \mathrm{~cm}^{-3}$, both with and without UV. The upper two points show that an increase in the boron flux by a factor of two from $2.5 \times 10^{13} \mathrm{~B} \mathrm{~cm}^{-2} \mathrm{~s}^{-1}$ to $5 \times 10^{13} \mathrm{~B} \mathrm{~cm}^{-2}$ increases the amount of diffusion by almost the same factor, from 60 to $110 \mathrm{~nm}$ with no UV. This difference presumably arises from changes in the as-implanted damage structures with ion flux at $200 \mathrm{~K}$. Implanting with the UV lamp on resulted in a reduction of the diffusion length by $30 \mathrm{~nm}$ at both ion fluxes. It is not clear whether this results from a change in the nature of the implantation damage or an overall reduction of it. TEM observations of these samples to determine the damage microstructure should shed some light on these questions.

\section{CONCLUSIONS}

The effect of electric fields and charge carrier injection on ion implantation damage in silicon has been investigated. In each case, we found the overall effect to be a reduction in the total amount of damage. We believe the effects are due to changes in the charge state of defects created during implantation, which affects their mobility and their Coulombic interactions. However, electric field-induced redistribution, and possibly recombinationenhanced lowering of energy barriers also play a rôle.

\section{ACKNOWLEDGEMENTS}

This research is supported by the National Science Foundation grant DMR-9215538. Research at ORNL was sponsored by the U.S. Department of Energy, under contract DE-AC05-840R21400 with Martin Marietta Energy Systems, Inc.

\section{REFERENCES}

1. Y. N. Erokhin, J. Ravi, C. W. White and G. A. Rozgonyi, Nucl. Instr. and Meth. B96, 223-226 (1995).

2. Y. N. Erokhin, J. Ravi, G. A. Rozgonyi, and C. W. White, Appl. Phys. Lett. 66, 1656-1658 (1995).

3. J. Ravi, Y. N. Erokhin, S. Koveshnikov, C. W. White, and G. A. Rozgonyi, Mat. Res. Soc. Symp. Proc. 316, 105 (1994).

4. J. R. Troxell, A. P. Chatterjee, G. D. Watkins and L. C. Kimerling, Phys. Rev. B 19, 5336 (1979).

5. J. Ravi, Y. N. Erokhin, C. W. White, and G. A. Rozgonyi, Mat. Res. Soc. Symp. Proc. 373, 1 (1995).

6. W. H. Weisenberger, S. T. Picraux, and F. L. Vook, Radiation Effects 9, 121-125 (1971).

7. J. Ravi, Y. N. Erokhin, G. A. Rozgonyi, and C. W. White, Appl. Phys. Lett. 67, 2158-2160 (1995). 